\title{
Effectiveness of Structural Teaching Programme on Knowledge Regarding the Contraceptive Method among the Eligible Couples
}

\author{
Vikas Choudhary ${ }^{1}$, Parul Saini ${ }^{2}$ \\ ${ }^{1}$ Tutor, M M College of Nursing, Mullana, Ambala, Haryana. \\ ${ }^{2}$ Tutor, College of Nursing, AIIMS, Rishikesh.
}

\begin{abstract}
Couples are using contraceptive methods because they never want unhealthy, unwanted child. They make a plan for child born and give space between two children. They use contraception to prevent sexual transmitted disease. ${ }^{1}$ The present study was conducted to find out the effectiveness of structural teaching programme (STP) regarding contraceptive method among eligible couples. The purpose of this study was to educate the couples to prevent unwanted pregnancy and day to day activities to maintain stranger vigilance for early signs of STD. This study is aimed at improving the knowledge of eligible couples. An evaluative approach with pre experimental design was used for the study. The sample consisted of 60 eligible couples. Samples were selected by purposive sampling technique. Data was collected by Administering structured knowledge questionnaire prior and after the administration of structural teaching programme. The studyFindings revealed that knowledge gained through STP was good, as it was evident withpre-test and post-test mean knowledge score of eligible couples in control and experimental group, the pre-test and post-test mean knowledge score of control group $(25.42,24.02)$ was not statistically significant, whereas the pre-test and post-test mean knowledge score of experimental group $(23.18,36.54)$ was highly significant at $p<0.001$ concluded that there is significant difference in the understanding of eligible couples regarding contraceptive methodby using a structured teaching programme.
\end{abstract}

Key words: Effectiveness; STP; contraception, eligible couples.

\section{Introduction}

In normal sexual life; a woman can conceive within 24 hours of release of mature ovum if it enters the fallopian tube and meets with sperm but the conception can be prevented by using any of the contraceptive method. ${ }^{1}$ Contraception is an effective method to reduce maternal mortality by preventing unwanted pregnancy and unsafe abortion by and by promoting healthy pregnancies. ${ }^{2}$ The knowledge of contraception is very effective because couples can make decision about the timing and number of child they want actual. For many years, family planning experts have generally agreed that a 24 months or 2 year birth interval is important for infant, child and maternal health. Studies have shown that birth intervals less than 2 year are associated with adverse prenatal and maternal outcomes. ${ }^{3}$

The knowledge of the contraception is one of the most basic and essential health care services and smaller families are better able to meet their house hold and economic needs. It is used to prevent infant death, reduce poverty and population growth. ${ }^{4}$ The conventional contraceptive is used to denote the methods that require action at the time of sexual intercourse. E.g., condoms, spermicidal, etc. Each contraceptive method have its unique advantages and disadvantages. The success of any contraceptive method depends not only on its effectiveness in preventing pregnancy but on the rate of continuation of its proper use. ${ }^{5}$ Many women fear of side effect of contraception. Some women lack knowledge about contraceptive method or they may not have access to the method they want because of weakness in services and supplies. ${ }^{6}$ The investigator has observed that the women from the rural area are most prone to develop complication associated with pregnancy and child birth due to fewer intervals between pregnancies and due to multi parity.

\section{Objectives:}

1. To assess the knowledge regarding the contraceptive method before administering structural teaching programme.

2. To determine the effectiveness of structural teaching programme after administration of structural teaching programme in experimental group.

3. To determine the association between the knowledge level regarding contraceptive method and selected demographical variables

\section{Material \& Method}

An evaluative research approach using the pre-test $(\mathrm{O} 1)$ and post-test $(\mathrm{O} 2)$ was used for the study and Pre experimental design was used. Data were collected from eligible couples of selected community areas by 
using demographic Performa and structured questionnaire. The sample for the study was consisting of 60 eligible couples and simple random sampling technique was used.

The tool consists of demographic Performa in Part I and Structured questionnaire to assess the knowledge of eligible couples in Part II. The tool was validated by 3 experts, from specified field such as community health nursing, Medical Surgical nursing. The investigators modified the final tools based on expert's suggestions. The tools were translated from English to Hindi and confirm the appropriateness of the language used in framing the items.

The investigator had obtained formal permission from the selected community to conduct the study. The investigator gave self-introduction and purpose of the study was explained to the sample, informed written consent were obtained from them.

\section{Major Findings}

- In experimental group majority of eligible couples (38.67\%) were 21-25 age group whereas In control group majority of eligible couples (36.3\%) were 25-30 year of age. In experimental group majority of eligible couples $(34.67 \%)$ were higher secondary and in control group majority of eligible couples $(24.6 \%)$ were higher secondary.

- Regarding the comparison of pre-test and post-test mean knowledge score of eligible couples in control and experimental group, the pre-test and post-test mean knowledge score of control group (25.42, 24.02) was not statistically significant, whereas the pre-test and post-test mean knowledge score of experimental group $(23.18,36.54)$ was highly significant at $\mathrm{p}<0.001$.

- Thus it was concluded that structured teaching program had definite impact to increase the knowledge level of eligible couples in experimental group.

- According to percentage distribution, in control group majority of eligible couples had below average pre-test $(72 \%)$ and post-test $(82 \%)$ knowledge score whereas in experimental group $(74 \%)$ had below average pre-test knowledge score followed by (20\%) excellent, (75\%) good and (5\%) average post-test knowledge score.

- According to areas of knowledge, in control group both pre-test and post-test mean knowledge score of eligible couples was lowest in the area of prevention $(40.16 \%),(41.48 \%)$ followed by risk factors $(52.64 \%),(54.72 \%)$ and general information of contraceptive methods $(56.64 \%)$, (59.48\%) respectively. Similarly in experimental group pre -test mean knowledge score of mothers was lowest in area of prevention $(44.48 \%)$, followed by risk factors $(51.32 \%)$ and general information of contraceptive methods $(59.32 \%)$. Whereas the post-test mean knowledge score was highest in the area of general information of contraceptive methods $(77.32 \%)$ followed by prevention $(74.84 \%)$ and risk factors $(71.06 \%)$ respectively.

- There was statistically significant effect of education status of eligible couple, occupation, income, No. of children, education of husband, occupation of husband, type of family, health status of mother and size of family regarding the contraceptive methods in control and experimental group.

\section{Conclusion}

Pre-test and post-test mean knowledge score of eligible couples in control and experimental group, the pre-test and post-test mean knowledge score of control group $(25.42,24.02)$ was not statistically significant, whereas the pre-test and post-test mean knowledge score of experimental group $(23.18,36.54)$ was highly significant at $\mathrm{p}<0.001$ This indicates that the structured teaching programme was effective to improve the knowledge of couples regarding contraceptive method.

\section{References}

[1]. Brunner \&Suddarth's, "Textbook of Medical and Surgical Nursing", $10^{\text {th }}$ edition, Publishing by Lippincott Williams \& Wilkins; 2004.

[2]. RGUHS Journal of Medical Sciences, April 2012, Vol 2, Issue 2. P 102 - 104

[3]. Ebersole. Toward Healthy aging. Human needs and Nursing response. $5^{\text {th }}$ ed. Newyork:Mosby; 1998

[4]. ArunaDubey, SeemaBhasin, Neelima Gupta and Neeraj Sharma. A Study of Elderly Living in Old Age Home and Within Family. University of Jammu, Jammu \& Kashmir, India; 2011.

[5]. RGUHS Journal of Medical Sciences, April 2012, Vol 2, Issue 2. P 102 - 104.

[6]. Zeleznik,Danica,UniversityofOulu, http://herkules.oulu.fi/isbn9789514286377/ 